\title{
LA-UR- $98-2619$
}

Approved for public release; distribution is unlimiteo.

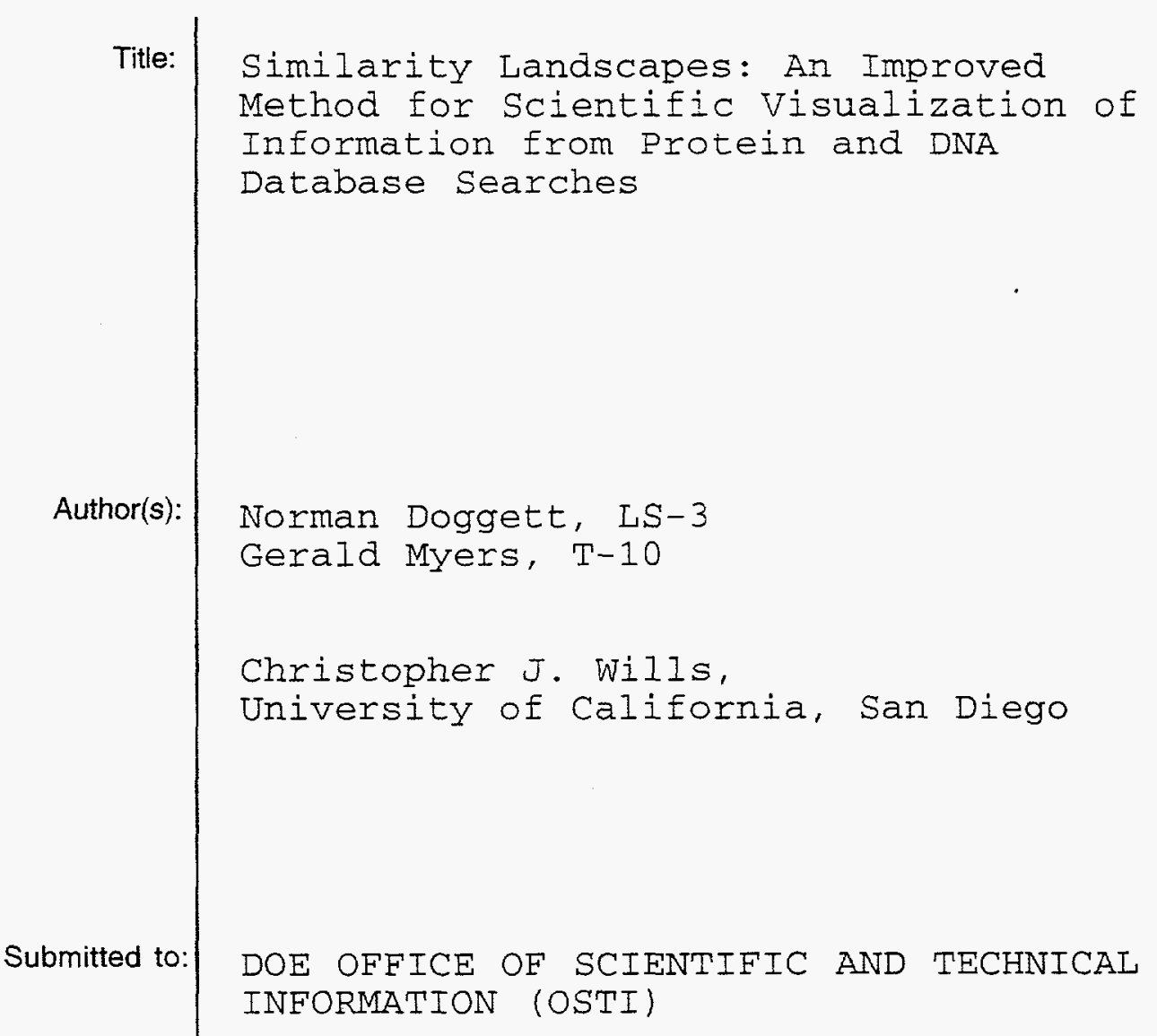

INFORMATION (OSTI)

\section{Los Alamos}

NATIONALLABORATORY

Los Alamos National Laboratory, an affirmative actionvequal opportunity employer, is operated by the University of California for the

U.S. Department of Energy under contract W-7405-ENG-36. By acceptance of this article, the publisher recognizes that the U.S

Government retains a nonexclusive, royalty-free license to publish or reproduce the published form of this contribution, or to allow

others to do so, for U.S. Government purposes. Los Alamos National Laboratory requests that the publisher identify this article

as work performed under the auspices of the U.S. Department of Energy. The Los Alamos National Laboratory strongly supports

academic freedom and a researcher's right to publish; as an institution, however, the Laboratory does not endorse the viewpoint

of a publication or guarantee its technical correctness. 


\section{DISCLAMMER}

This report was prepared as an account of work sponsored by an agency of the United States Government. Neither the United States Government nor any agency thereof, nor any of their employees, makes any warranty, express or implied, or assumes any legal liability or responsibility for the accuracy, completeness, or usefulness of any information, apparatus, product, or process disclosed, or represents that its use would not infringe privately owned rights. Reference berein to any specific commercial product, process, or service by trade name, trademark, manufacturer, or otherwise does not necessarily constitute or imply its endorsement, recommendation, or favoring by the United States Government or any agency thereof. The views and opinions of authors expressed herein do not necessarily state or reflect those of the United States Government or any agency thereof. 


\section{DISCLAIMER}

Portions of this document may be illegible in electronic image products. Images are produced from the best available original document. 


\title{
Similarity Landscapes: An Improved Method for Scientific Visualization of Information from Protein and DNA Database Searches
}

\author{
Norman Doggett* and Gerald Myers \\ Los Alamos National Laboratory \\ Christopher J. Wills* \\ University of California, San Diego
}

\begin{abstract}
This is the final report of a three-year, Laboratory Directed Research and Development (LDRD) project at the Los Alamos National Laboratory (LANL). We have used computer simulations and examination of a variety of databases to answer questions about a wide range of evolutionary questions. We have found that there is a clear distinction in the evolution of HIV-1 and HIV-2, with the former and more virulent virus evolving more rapidly at a functional level. We have discovered highly non-random patterns in the evolution of HIV-1 that can be attributed to a variety of selective pressures. In the course of examination of microsatellite DNA (short repeat regions) in microorganisms, we have found clear differences between prokaryotes and eukaryotes in their distribution, differences that can be tied to different selective pressures. We have developed a new method ("topiary pruning") for enhancing the phylogenetic information contained in DNA sequences. Most recently, we have discovered effects in complex rainforest ecosystems that indicate strong frequency-dependent interactions between host species and their parasites, leading to the maintenance of ecosystem variability.
\end{abstract}

\section{Background and Research Objectives}

Our goal has been to answer questions about the nature of non-random patterns that are observed in evolutionary processes. Are they truly non-random? To what extent can the patterns observed be attributed to selection and other non-random processes, and to what extent might they have been generated by random events that sometimes mimic non-random ones?

The enhanced computer power provided by this project has enabled us to explore the value of using repeated simulations of shuffled or scrambled data sets. This has enabled us to see patterns in data sets that have often eluded other investigators. We have discovered non-random patterns, most easily explained by selection, in HIV virus evolution and in the

\footnotetext{
*Principal Investigators, e-mail: doggett@lanl.gov and cwills@ucsd.edu
} 
evolution of complex rainforest ecosystems. We are continuing to attack the question of whether the resemblance between very distantly related proteins can be attributed to common ancestry or whether they could have arisen by convergence.

\section{Importance to LANL's Science and Technology Base and National R\&D Needs}

The techniques we have developed for examining the HIV database will be useful for analyzing other virus databases and other DNA databases. The statistical randomization methods we have developed will be useful for examining the extensive databases now being collected from complex ecosystems. We intend to continue collaborations with members of the HIV database group at LANL.

\section{Scientific Approach and Accomplishments}

One of the long-standing problems with examining molecular data from natural populations is that it is very difficult to determine simply from frequencies of alleles what forces have been operating on the population in the past. Have frequencies of alleles been influenced by selective forces, or are they simply the result of some combination of chance sampling events from one generation to the next combined with fluctuations in population size and splittings and fusions of populations in the past? Any distribution of allele frequencies can have a number of possible sources. This difficulty underlies all studies of molecular evolution on present-day populations (Lewontin 1974).

A somewhat different but related difficulty makes it hard to interpret data from another type of molecular evolution study. It is commonplace, once a gene has been found, to search the data base for homologues of that gene. If the homologues resemble the gene closely, it is safe to assume that they had a common ancestor, but if the resemblance is a slight one it is very hard to determine whether the resemblance is due to chance, to an evolutionary convergence due to similar selection on similar amino acid sequences, or to true common ancestry.

In the course of this project, we have addressed both these problems, the first more successfully than the second. We have accomplished the following:

1. Topiary Pruning. One of us (CW) has developed a new method, topiary pruning, for increasing the amount of phylogenetic information in a data set (Publication 8). This method has been used to show that HIV-1 and HIV-2 have undergone what appear to be very similar sets of events during the course of their recent evolution, at least at the nucleotide level (Publication 4). This apparent similarity is an illusion, however, for Wills and Myers have been able to show that at the level of functionality, HIV-1 has undergone two to three 
times as much evolution as its less virulent relative HIV-2 (Publication 10). This could be revealed by examining the distribution of short sets of amino acids in the gene coding for the heavily glycosylated envelope protein of these two viruses. These short sequences, which mark glycosylation sites, have undergone much more evolutionary change in the more virulent virus, perhaps an indication of the strong interactions between this virus and the host immune system. Here, the effect of selection could not be detected by simple examination of the nucleotide sequences themselves. The implications of such observations for the evolution of diseases in general have been explored by Wills in a recent book (Publication 6). More recently, we have used topiary pruning to explore the evolution of mitochondrial DNA in humans and the great apes (Publication 3).

2. Distribution of Substitution Types. Wills has developed a method for examining in detail the distribution of types of base substitutions that take place during the course of evolution. It has been known for some time that an excess of so-called non-synonymous substitutions, those that result in an amino acid substitution, indicates evidence for directional selection, while an excess of synonymous substitutions. those that do not result in an amino acid change, indicates that purifying selection - selection against change - has been taking place (Reference 4). The problem has been that it has been difficult to determine with certainty whether such differences between observed and expected numbers are significant. Wills has repeatedly shuffled HIV-1 data sets according to specific rules designed to preserve the phylogenetic history of the data sets but otherwise randomize the bases, and has found that a high complex set of events have shaped these genes - a time-dependent mix of directional and purifying selection, along with a large role for chance events. This work has been submitted for publication (Publication 5).

3. Repeated bases and codons in genomes. Graduate student Dawn Field in Wills' lab has observed long runs of repeated bases and codons in the genomes of a number of simple organisms (Publication 1). More recently Field has developed methods for looking at observed and expected numbers of runs of the same base in entire genomes. She finds very different distributions of these runs in eukaryotic and prokaryotic genes. In particular, there is strong evidence that long runs of the same base are selected against in prokaryotes, while mutation pressure allows such runs to build up to large numbers in eukaryotes. She is coupling these observations with experiments on the runs that she has found in the yeast Saccharomyces cerevisiae, to try to determine whether these very different distributions are due to mutation pressure and purifying selection alone, or whether directional selection may have played a role. This work has just been submitted for publication (Publication 2).

4. Repeated-Randomization Process. The repeated-randomization process has recently proved to be very useful in determining the extent of non-random processes that are 
taking place in complex ecosystems such as tropical rainforests. It has been very difficult to see why tropical ecosystems should be so species-rich, since their environment tends to be remarkably uniform. A large number of species implies a large number of ecological niches, and it is not obvious what those niches might be. Epidemiologist Jan Gillett first pointed out that disease organisms will provide such niche-diversity (Reference 3), and ecologists since have proposed various models that take pests into account (Refs. 1 and 2). It has been a challenge to collect data sets of sufficient size for the effects of pests to be seen. We have now examined two of the data sets, one from Panama and one from Malaysia, and find strong indications of the role of pests in the maintenance of diversity. The first of these analyses has just been published (Publication 9). This result may appear at first sight to be very different from the question of what maintains gene frequency distributions in natural populations, but there are indications that similar balancing forces are operating in the rainforest and at such complex human loci as MHC (Publication 7 and Reference 6).

5. Distantly Related Protein Sequences. We have been less successful in making progress on the second problem that of the resemblance between distantly related protein sequences. We hope to apply to the collaborative university-laboratory research (CULAR) program to complete this study.

\section{Publications}

1. Field, D. and C. Wills, "Long, polymorphic microsatellites in simple organisms," Proc. Roy. Soc. London B 263: 209-215 (1996).

2. Field, D. and C. Wills, “Abundant, polymorphic microsatellites in yeast, contrasted with far fewer such microsatellites in six prokaryotic genomes, show a differential role for selection in eukaryote and prokaryote microsatellite evolution," Proc. Natl. Acad. Sci. U.S. (submitted).

3. Gagneux, P., C. Wills, P. A. Morin, C. Boesch and D. S. Woodruff, "Resolution of branching order and detection of different demographic histories in recent hominoid evolution," Science (submitted).

4. Wills, C. "Topiary pruning of the HIV and SIV phylogenetic tree.," AIDS Research and Human Retroviruses 11: 1417-1419 (1995).

5. Wills, C. "Directional selection acting on HIV-1 genes is correlated with codon mutability and is most pronounced among recently diverged sequences," Proc. Natl. Acad. Sci. U.S. (submitted).

6. Wills, C. Plagues: Their Origin, History and Future, Harper-Collins (1996).

7. Wills, C. "Safety in diversity," New Scientist 149: 38-42 (1996). 
8. Wills, C. "Topiary pruning and weighting reinforce an African origin for the human mitochondrial DNA tree," Evolution 50: 977-989 (1996).

9. Wills, C. and R. Condit, "Strong density- and diversity-related effects help to maintain tree species diversity in a neotropical rainforest," (1997).

10. Wills, C., A. Farmer and G. Myers, "Rapid sequon evolution in HIV-1," AIDS Res. Human Retroviruses 12: 1383-1384 (1996).

\section{References}

[1] Clark, D. A. and D. B. Clark, "Spacing dynamics of a tropical rainforest tree: evaluation of the Janzen-Connell model," Amer. Nat. 124: 769-788 (1984).

[2] Connell, J. H. "On the role of natural enemies in preventing competitive exclusion in some marine animals and in rain forest trees," in Dynamics of populations, edited by P. J. Den Boer and G. Gradwell, PUDOC, New York (1971).

[3] Gillett, J. B. "Pest pressure, an underestimated factor in evolution," pp. 37-46 in Taxonomy and Geography, a Symposium, edited by D. Nichols. London Systematics Association, London (1962).

[4] Hughes, A. L. and M. Nei, "Nucleotide substitutions at major histocompatibility complex class II loci: evidence for overdominant selection," Proc. Natl. Acad. Sci. U.S. 86: 958-962 (1989).

[5] Lewontin, R. C. The Genetic Basis of Evolutionary Change, Columbia University Press, N.Y. (1974).

[6] Wills, C. and D. R. Green, "A genetic herd immunity model for the maintenance of MHC polymorphism," Immunol. Rev. 143: 263-292 (1994). 